\title{
Validation of the Information-Technology-Enabled Interaction Instrument in Contemporary Chinese Context
}

\author{
Miao $\mathrm{Li}^{1}{ }^{1} * \mathbb{D}$, Xin $\mathrm{Yu}^{2}$ and Chunhao $\mathrm{Li}^{1}$ \\ 1 School of Management, Jilin University, Changchun 130022, China; lich@jlu.edu.cn \\ 2 Business School, NanJing XiaoZhuang University, Nanjing 211171, China; yuxin123@njxzc.edu.cn \\ * Correspondence: miao@jlu.edu.cn
}

Received: 19 October 2020; Accepted: 3 December 2020; Published: 8 December 2020

\begin{abstract}
Practitioners and researchers have shown great interest in information-technology (IT)-enabled interactions across partnering firms and developed instruments for measuring it. However, those instruments might have been under criticism as they were developed before the widespread adoption of the new IT applications like video conferences, DingTalk and WeChat Moments among Chinese managers for the last five years. The purpose of this study is to validate the instrument of IT-enabled formal and informal interactions for the contemporary Chinese context. First, the study reviews the literature on IT-enabled interfirm interactions and designs an open questionnaire through in-depth interviews. Answers from 85 pairs of suppliers and manufacturers are coded and the preliminary item pool is generated through the qualitative analysis. Next, a small-scale pretest with 120 manufacturing firms is conducted to purify and modify the item pool. Finally, a large-scale analysis with 336 manufacturing firms is conducted to check the reliability and validity of the measurements. The finalized scale yields six items measuring IT-enabled formal interaction and five items measuring IT-enabled informal interaction, among which six are newly derived in this study. The validated instrument reveals satisfactory reliability and validity and can serve as the basic instruments for future research on IT-enabled interactions.
\end{abstract}

Keywords: IT-enabled interaction; relationship management; mutual trust; instrument validation

\section{Introduction}

Effective interactions across partnering firms could enhance mutual trust, promote collaborative efforts and impede opportunism [1-3], thus contributing greatly in developing and marinating cross-organizational relationships. To improve the quality of interfirm interactions, many firms in China utilize information technology (IT hereafter) to conduct business affairs with each other. For instance, Unilever China, Wal-Mart and Nestle adopt the cross-organizational IT systems to manage their large and complex supply chain systems. Using the IT systems, those companies could effectively trace the state of procurement, distribution, shipment and payment [4]. Besides the formal business affairs, firm managers could also socialize informally with each other to enhance mutual relationships with the aid of social media, such as liking, sharing and commenting on WeChat or Weibo [5]. Over the last five years, interfirm interactions in China have dramatically shifted from offline to the IT platforms to respect the governmental policy of Made in China 2025 under Industry 4.0 visions. Moreover, the breakout of novel coronavirus in 2019 has further pushed firm partners to perform remote interactions rather than face-to-face communication. As the report of China Internet Watch suggests, the active users on WeChat and QQ mobiles in China had risen to 1.15 billion and 653.4 million, respectively, by the third quarter in 2019 [6]. 
With the emerging importance of using IT for interactions, researchers have made great efforts in investigating IT-enabled interfirm interactions from different perspectives. First are the studies which identify the drivers and consequences of IT-enabled interactions. They find that organizational factors such as cultural conflict and organizational support, relational factors like relationship-specific investment and technical factors like the employees' IT capability could impact the quality of IT-enabled interaction [7-9]. They also find that the adoption of IT in interfirm interactions could improve both relational outcomes like trust and economic performance of both partners [10-12]. Second are those that identify the types or functions of IT-facilitated interfirm interactions [13-15]. As suggested by Li and her colleagues [13], IT-enabled interactions could be categorized into formal and informal types according to the purpose of the interaction. The formal type of IT-enabled interactions is contract-related and usually performed with the purpose to complete business-related tasks, such as transmitting purchase orders and coordinating inventory schedules via business software. The informal type of IT-enabled interaction is relation-oriented and mainly related to online socializing activities across the boundary spanners with the purpose to strengthen relationships. After reviewing prior literature, we find that many studies focus on the formal type of IT-enabled interaction [16-19], while only four studies focus on the informal type of IT-enabled interaction [13,20-22]. Third is related to the measurement of IT-enabled interaction, with [23] and [24] being the recent examples.

The current research belongs to the third category. First, this study aims to validate the instrument to measure IT-enabled formal interaction as provided previously. Studies on IT-enabled formal interaction in prior literature involve two sub-types, namely, structured and unstructured ones. The structured interactions are mainly related to business processes integration which gets automatically prearranged by IT like electronic data interchange (EDI hereafter) platforms [25-27]. The unstructured interactions are mainly related to business communication over IT tools such as e-mail and video conference $[28,29]$. Both structured and unstructured formal interactions are necessary in completing transactions. Focusing on one type while leaving the other absent will make the understanding of IT-enabled formal interaction fragmented. However, most prior studies focus on either the structured or the unstructured type. One exception is Li and her colleagues' research [13] which tried to include both types of interaction in the measurement of IT-enabled formal interaction. However, their empirical results indicated that the items of unstructured interaction ("We often transfer business materials with each other through information technologies like E-mail"; "We hold video conferences on a regular basis") got deleted due to low factor loadings. What they actually measure is structured formal interaction solely. However, their data were collected in 2015 by which time video conferences and DingTalk had not been widely adopted by firm managers. Over the last five years, many new IT tools such as big data, electronic payment, DingTalk and video conferences have become greatly prevalent in China [30,31]. The measurement in prior literature could not capture the development of those technologies, which may lead to an incomplete understanding of IT-enabled formal interaction. Thus, it is necessary to validate the instrument of IT-enabled formal interaction consisting of both structured and unstructured types with contemporary data in China.

The second purpose of this study is to validate and expand the measurement of IT-enabled informal interaction provided by Li and her colleagues [13]. To the best of our knowledge, we find only four studies about IT-enabled informal interactions in prior literature. Three studies focus on the socializing activities across boundary spanners over Twitter and LinkedIn [20-22]. All three studies failed to provide the measurement of IT-enabled informal interaction by utilizing the qualitative methods such as in-depth interviews. Only Li and her colleagues [13] provide the scale to measure IT-enabled informal interaction with three items, i.e., "We follow one another on social media"; "We often chat about family or interests over the internet with one another in our spare time"; "We often interact on social media, such as posting or forwarding interesting links to one another, making comments, and opting in". However, their sample was collected in 2015 and the measurement mainly captures the interactions within focal dyadic relations. During the past five years, many new IT functions such as WeChat Moments, online games and WeChat groups have prevailed in China $[5,32]$. 
Those applications could not only facilitate the socialization between two parties, but also enlarge both partners' interaction with common friends on Weibo or QQ. By tracing each other's social ties and interacting with common third parties, the focal dyad relations could be tied more closely. Thus, that scale of Li and her colleagues [13] should be extended and updated for a more comprehensive understanding of IT-enabled informal interaction.

We believe that the contribution of this study is obvious. As suggested by Straub [33], the instrument to measure IT-related concepts should keep updating and match with the current state of the development of IT. Apparently, the efficiency and effectiveness of IT-enabled interactions largely depends on the functions of IT tools in use. However, the existing measurement of IT-enabled interaction could not capture the development and widespread adoption of the new IT functions such as DingTalk, video conferences and WeChat Moments. Investigations about IT-enabled interactions without an adequate understanding of those new IT tools might be insufficient and antiquated. Moreover, the lack of inadequate tools to measure IT-enabled interactions would definitely hinder the process of related quantitative research. This paper, by validating the instrument of IT-enabled formal and informal interactions for the contemporary Chinese context, could well fill in the above-mentioned research gap. The developed instruments can be used as a springboard for theoretically motivated studies, allowing researchers in both information system and marketing strategies to develop a cumulative research tradition.

The rest of the paper is arranged as follows. First, a literature review about the measurement of IT-enabled interactions across partnering firms is provided to further identify the contribution of this paper. Next, the research method to develop scale is described. Then, the paper presents a series of statistical assessments of the validated instrument. Finally, the findings, conclusions and implications are presented.

\section{Existing Knowledge of Measurement of IT-Enabled Interaction}

\subsection{Definition}

Before reviewing knowledge about the instrument to measure IT-enabled interaction, the definition of the construct should be provided. In this paper, IT-enabled interaction is defined as mutual or reciprocal actions conducted by partners in supplier-buyer relations to exert influence upon each other through the use of IT [1]. Following Li and her colleagues [13], IT-enabled interaction could be further categorized into formal and informal types according to the purpose of the interaction. "IT-enabled formal interaction" refers to the IT-aided, contract-based bilateral activities across partner firms which aimed at negotiating and safeguarding contracts. Special emphasis is given in the current study that IT-enabled formal interaction should involve all types of contract-related activities, ranging from the unstructured commercial communication facilitated by IT such as DingTalk to the structured IT-based business procedure management such as electronic payment over Alipay and tracing business orders via EDI systems. "IT-enabled informal interaction" is defined as the partners' bilateral socialization tactics beyond official trade settings via various social platforms [13]. Compared with the formal type of interaction which focuses on transmitting contract-related information, informal interactions mainly involve the exchange of socializing signals to reinforce relationships.

\subsection{Research Context}

Research context should also be provided before the literature review. As suggested by Malone and his colleagues [34], IT could shape two types of governance mechanism, namely, electronic market and electronic hierarchy. Electronic markets consist of a market maker that manages the online market and the participant firms such as suppliers and buyers, with Alibaba and Ebay being two examples. Electronic hierarchy consists of solely the participant firms who have stable cooperative relationship with each other and utilize IT for improving the exchange efficiency. One typical example was the partnership between WalMart and its distributors within the supply chain system. Interactions within 
the two types of governance mechanism differ significantly from each other. To make the research context clear, this paper focuses solely on electronic hierarchy context rather than electronic markets. Besides, the study also limits the IT-enabled interactions to vertical relations between suppliers and buyers rather than horizontal relations such as alliance members, because the interactive activities within those two relations also differ from each other greatly. Moreover, as the types of IT in use differ significantly between the service industry and manufacturing industry, this study focuses solely on the manufacturing firms rather than the service industry to make the developed scales more appropriated and more applicable.

\subsection{Searching and Filtering Method}

Focusing on the research context set previously, this study conducts a literature review to map the current state of prior knowledge about the measurement of IT-enabled interfirm interactions following Webster and Watson' suggestions [35]. Specifically, the authors searched top journals in information system, computer science and marketing strategy using the key words "information technology + interfirm/cross-organizational" "information technology + supplier/buyer" "social media + interfirm/cross-organizational" "information system + interfirm/cross-organizational" "electronic + interfirm/cross-organizational" "EDI + interfirm/cross-organizational" and so on in the online databases EBSCO and Google Scholar. Papers published on international conference proceedings such as IMP conference are also included. After reviewing abstracts, the author and the partner found 166 articles with typical descriptions of IT-enabled interactions. Additional filtering criteria were followed as: (a) Studies that did not provide the scales with items describing patterns of activities or routines that firms interact with each other; (b) interaction within horizontal relations; (c) interactions take place on electronic markets rather than electronic hierarchy context. This procedure involved all the authors and two additional doctoral students in the information system research area. In the end, we found 48 records.

\subsection{Measurement of IT-Enabled Interaction}

We sorted the final 48 records after comparing the measuring items and found that the type of IT-enabled interaction with empirical measurement identified by prior studies could be categorized into formal and informal types, which is consistent with the classification provided by $\mathrm{Li}$ and her colleagues [13]. Table 1 provides the list of representative studies, including the key constructs, the description of the measurement and the facilitated IT tools.

Table 1. Construct and Measurement of information-technology (IT)-enabled Interactions.

\begin{tabular}{|c|c|c|c|}
\hline $\begin{array}{l}\text { Representative } \\
\text { Studies }\end{array}$ & Construct & Description of the Measure & IT in Use \\
\hline \multicolumn{4}{|c|}{ IT-enabled formal interactions } \\
\hline$[17,18,25-27,36,37]$ & $\begin{array}{c}\text { Vertical } \\
\text { Integration }\end{array}$ & $\begin{array}{l}\text { Structured interaction: } \\
\text { Whether data are exchanged in electronic form in } \\
\text { terms of purchasing, engineering, quality, } \\
\text { production, control, transaction and payment and } \\
\text { other business procedures. }\end{array}$ & $\begin{array}{l}\text { EDI } \\
\text { (in supply } \\
\text { chain) }\end{array}$ \\
\hline$[38]$ & $\begin{array}{c}\text { Prevalence of EDI } \\
\text { Use }\end{array}$ & $\begin{array}{l}\text { Structured interaction: } \\
\text { The percentage that the partner get involved in } \\
\text { different types of EDI transaction. }\end{array}$ & $\begin{array}{l}\text { EDI } \\
\text { (in supply } \\
\text { chain) }\end{array}$ \\
\hline$[13,39,40]$ & $\begin{array}{l}\text { Electronic } \\
\text { Information } \\
\text { Transfer }\end{array}$ & $\begin{array}{l}\text { Structured interaction: } \\
\text { The regulated flow of information on coordinating } \\
\text { and monitoring supply chain activities from one } \\
\text { party to another. }\end{array}$ & $\begin{array}{l}\text { EDI } \\
\text { (in supply } \\
\text { chain) }\end{array}$ \\
\hline
\end{tabular}


Table 1. Cont.

\begin{tabular}{|c|c|c|c|}
\hline $\begin{array}{l}\text { Representative } \\
\text { Studies }\end{array}$ & Construct & Description of the Measure & IT in Use \\
\hline [41] & $\begin{array}{l}\text { Back-end } \\
\text { integration }\end{array}$ & $\begin{array}{l}\text { Structured interaction: } \\
\text { The degree to which the firm's back-office } \\
\text { databases is electronically integrated to the supply } \\
\text { chain systems to facilitate information sharing } \\
\text { along the value chain. }\end{array}$ & $\begin{array}{l}\text { Electronic } \\
\text { links and } \\
\text { back-office } \\
\text { databases }\end{array}$ \\
\hline [42] & IT Integration & $\begin{array}{c}\text { Structured interaction: } \\
\text { The extent to which a firm integrates and embeds } \\
\text { EDI into customer relationships } \\
\text { management (CRM). }\end{array}$ & $\begin{array}{c}\text { EDI } \\
(\mathrm{CRM})\end{array}$ \\
\hline [43] & $\begin{array}{c}\text { Interfirm IT } \\
\text { capability profiles }\end{array}$ & $\begin{array}{l}\text { Structured interaction: } \\
\text { Profile of the four kinds of IT capabilities, } \\
\text { including automation, coordination, integration } \\
\text { and synchronization in the previous year }\end{array}$ & $\begin{array}{l}\text { Logistic } \\
\text { Management } \\
\text { System }\end{array}$ \\
\hline$[28,29]$ & $\begin{array}{l}\text { Communication } \\
\text { tools adoption }\end{array}$ & $\begin{array}{c}\text { Unstructured interaction: } \\
\text { The degree of usage of each medium in } \\
\text { communicating transactional and } \\
\text { managerial information }\end{array}$ & $\begin{array}{l}\text { mail, } \\
\text { Internet, } \\
\text { video } \\
\text { conferencing }\end{array}$ \\
\hline \multicolumn{4}{|c|}{ IT-enabled informal interactions } \\
\hline [13] & $\begin{array}{l}\text { IT-enabled } \\
\text { informal } \\
\text { interaction }\end{array}$ & $\begin{array}{l}\text { The partners' bilateral socialization tactics beyond } \\
\text { official trade settings via various social platforms, } \\
\text { such as following each other and chatting about } \\
\text { private interests on WeChat. }\end{array}$ & $\begin{array}{l}\text { Twitter, } \\
\text { WeChat, } \\
\text { QQ }\end{array}$ \\
\hline
\end{tabular}

\subsubsection{IT-Enabled Formal Interactions}

Most of the previous literature focuses on the roles of IT-enabled formal interactions in interfirm relationship management, which are IT-aided and contract-based. Among them:

(1) Some researchers focus on the structured business integration which is usually automated by inter-organizational information systems such as the EDI platform. The integration activities range from electronic exchange of standardized documents to the integration and redefinition of fundamental supply chain management processes. Those interaction processes may have multiple functions, such as order tracking, market information sharing, production capacity coordinating, inventory level coordinating, material or component design supporting and so on. Concepts related to that interaction mainly include: (a) Vertical integration, which indicates the extent to which firms use EDI applications or other cross-organizational information systems to integrate or redefine the fundamental management processes between partners [25-27,36]. (b) Prevalence of EDI use, which reflects the percentage that the partner get involved in different types of EDI transaction [38]. (c) Electronic information transfer, which refers to the degree to which the firms transmit information between parties through electronic data integration systems $[13,39,40]$. (d) Back-end integration, which indicated the degree to which firms share back-office information to supply chain members via IT systems [41]. In addition to the above-mentioned studies which focus on the whole supply chain management practices, several studies focus on other business procedures such as customer relationship management and logistic management facilitated by information systems [42,43]. Yet all of those interaction activities are facilitated and automated by IT programs.

(2) Some researchers focus on the unstructured IT-enabled formal interaction, namely, business communication based on IT. They suggested that different IT tools might have different abilities to facilitate interfirm communication. Focusing on e-mail, internet, video conferencing and offline communication methods, they compared the impacts of each method on firms' abilities of exchanging transactional and managerial information with partners [28,29]. They measure that kind of 
interaction with the degree to which a firm utilizes a certain IT tool for communicating business or commercial information.

In sum, prior researchers exerted great efforts in studying IT-enabled formal interaction. However, they focused either on the structured formal interactions which are automated and prearranged by information systems like EDI or on the unstructured formal interactions facilitated by a single IT tool. A holistic understanding and the corresponding measurement of IT-enabled formal interaction should be given. One exception was Li and her colleagues' research [13] which tries to measure IT-enabled formal interaction with five items: "1. We often transmit business materials with each other through information technologies"; "2. We often transmit purchase orders with each other through information technologies"; "3. We often access each other's inventory or production levels through information technologies"; "4. We often coordinate inventory or production schedules with each other through information technologies"; and "5. We hold video conferences on a regular basis". Among those, items 1 and 2 measure unstructured interaction while the others measure unstructured interaction. However, in their final measurement, items 1 and 5 were deleted due to low factor loadings in confirmatory factor analysis. The real measuring scale captures only structured interaction. One reason for the low factor loading might be the un-prevalence of video conference in 2015 when Li and her colleagues collected the data. Besides, the information technologies facilitating those interactions could not capture the advancement of some new IT applications such as Alipay and Cloud Computing which get widely adopted by firms in China over the last five years. Thus, the scale of IT-enabled formal interaction should be updated.

\subsubsection{IT-Enabled Informal Interactions}

With the emergence of Web 2.0 such as Twitter and LinkeIn, firm managers increasingly utilize social media to socialize bilaterally with each other beyond official trade settings. Li and her colleagues [13] define such interactions as IT-enabled informal interaction. Among the original 166 publications we identified, only four studies investigated the functions of IT-enabled informal interactions [13,20-22]. Sigfussion and Chetty [20] argue that firms can network with potential partners on social platforms and explore the effects of digital networking through in-depth interviews with top managers and observing participants' activities on LinkedIn. Fisher and Reuber [21] found that entrepreneurs could utilize Twitter to communicate and socialize with partners with the aim to deploy social media for business benefits via in-depth interviews and archival data analysis. By interviewing professionals and observing LinkedIn group interactions, Quinton and Wilson [22] report that firms can use LinkedIn for interfirm relationship development. All three of the studies were conducted in foreign contexts where the applications of social media differ significantly from China and failed to provide the empirical measurement of IT-enabled informal interaction.

The only published study on the measurement of IT-enabled informal interaction is the instrument developed by Li and her colleagues [13]. As mentioned earlier, that study measured IT-enabled informal interaction with three items: "We follow one another on social media"; "We often chat about family or interests over the internet with one another in our spare time"; and "We often interact on social media, such as posting or forwarding interesting links to one another, making comments, and opting in". All the three items are related to interactions between focal dyadic partners. However, the sample of that study was collected in 2015 by which time many new IT applications like WeChat Moments, online games and WeChat Groups had not prevailed in China. Those new functions, by enlarging both partners' interactions with third parties, could further tie the focal dyadic relationship closer and thus could not be overlooked in the investigation of IT-enabled informal interaction. It is necessary to validate and extend the scale of IT-enabled informal interaction with updated data.

\section{Research Design}

In order to validate the measurement of IT-enabled formal and informal interaction in contemporary Chinese contexts, this study employs both qualitative and quantitative research designs following the 
procedures provided by Churchill [44]. Figure 1 presents the specific methodological steps, including (1) the preliminary item pool is derived by juxtaposing the findings from in-depth interviews and the existing items measuring IT-enabled formal and informal interaction; (2) four experts were invited to check the face and content validity of the preliminary items; (3) initial data were collected and the items was preliminarily purified via item analysis (including critical value test, item-to-total analysis and reliability analysis) and then construct validity analysis (i.e., exploratory factor analysis); (4) a second round of data were collected for further purification and refinement and the dataset was checked for non-response bias and common method bias; (5) the final instrument is derived after exploratory factor analysis (EFA), confirmatory factor analysis (CFA) and predictive validity analysis for checking the validity and reliability. The following section provides more details.

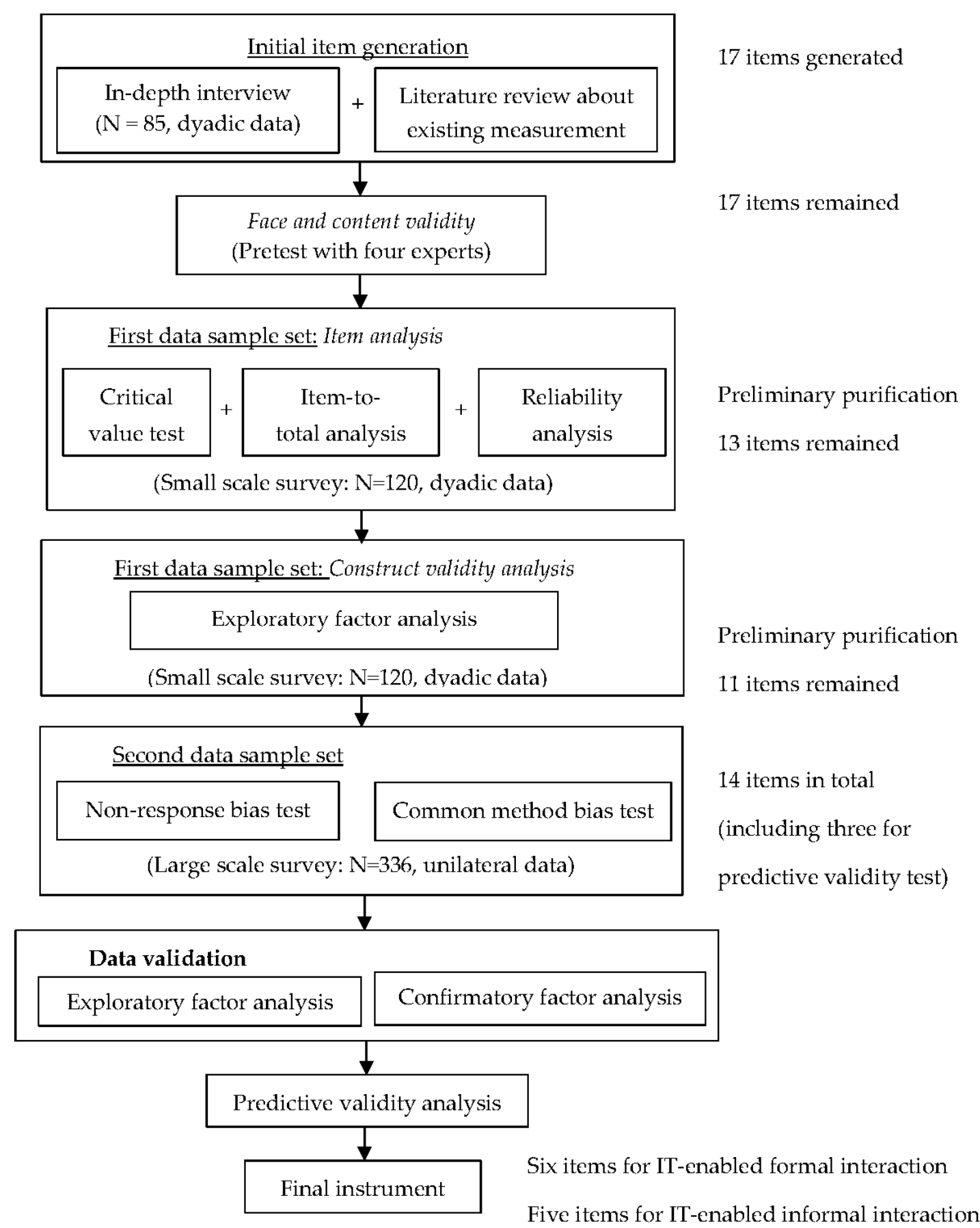

Figure 1. The methodological steps of instrument development. 


\subsection{Initial Item Generation}

In this initial stage, a preliminary and parsimonious pool of scale items measuring IT-enabled formal and informal interactions was derived using in-depth interviews. Then the derived items were compared with already existing measuring items of the two concepts, and merged together.

\subsubsection{Items Derived from In-Depth Interviews}

First, the authors designed a semi-structured questionnaire on IT-enabled interaction to obtain typical examples and expressions of the concept based on the advice from two experts in marketing and two experts in information system. Three sections consist of this questionnaire, namely, the demographic information, the illustration of the information technologies and the core open-ended questions. "Information technologies" refers here to a broad range of technologies involved in information processing and handling, such as computer hardware, software, telecommunications and office automation, digital electronics, social media and other information-processing technologies [45]. Since this study focuses on the electronic-hierarchy rather than the electronic-market context, we illustrate in particular that transactions conducted solely over Alibaba, Ebay and other electronic platforms are not allowed in the research context during the whole interview process. The open-ended questions mainly included "How do you understand IT-enabled interaction between the supplier and buyer?"; "Can IT facilitate the contract-related activities across different companies? Then how?"; "Can IT facilitate the informal socializing activities between the partners? Then how?"; and so forth. More details are presented in Table 2.

Table 2. The Semi-Structured Questionnaire.

\begin{tabular}{l}
\hline Demographic Information of the Respondent \\
\hline Your Age: \\
\hline Your Gender: Male/Female \\
\hline Education level: \\
\hline Working history in the current industry: () Years \\
\hline Working history in the current company: () Years \\
\hline Your position in your current company: \\
\hline Your department: \\
\hline Illustration of Several Concepts in Our Research: \\
\hline IT: Information technologies refer here to a broad range of technologies involved in information processing and \\
handling, such as computer hardware, software, telecommunications and office automation, digital electronics, \\
social media and other information-processing technologies. \\
Note: Electronic markets such as Alibaba and Ebay are not allowed in \\
\hline Open-Questions: \\
\hline Q1: Do you think IT can facilitate the interactions between your company and your partnering firm? \\
What aspects have IT covered over your interaction processes with your partner? \\
\hline Q2: Do you think IT-enabled interactions important? Please provide the reasons \\
\hline Q3: To which degree does your company rely on IT to conduct business with the partners? What kinds of IT \\
tools do you utilize? \\
\hline Q4: Besides the contract-related affairs, do you socialize with your partner via IT? How frequent do you \\
socialize online? Please provide three or more specific examples. \\
\hline Q5: How do you understand IT-enabled formal and informal interactions in your way \\
\hline
\end{tabular}

Next, we conducted a pretest with 15 full-time MBA/EMBA students to check the reliability of the open-questionnaire. All the respondents were selected using a purposive method, such as being knowledgeable about most of the interaction processes between their firms and the key supplier/buyer, 
being familiar with the information technology they use. Since the concept of IT-enabled interaction is supposed to capture or at least represents firm-level activities, the authors selected higher-level managers as the key respondents, such as the purchasing department head, the vice president and the chief executive officer (CEO). The industries of their respective companies cover a wide range in manufacturing industry, including machinery manufacturing, pharmaceutical manufacturing, electronic products manufacturing, garment manufacturing and so on.

The interview results suggest that the designed semi-questionnaire (Table 2) is ready for a large-scale survey. Thus, we further sent the semi-questionnaire to 350 manufacturing firms in Eastern China (Tianjin and Changchun), Western China (Xi'an and Henan) and Southern China (Guangzhou) through e-mails and face-to-face interviews. Participants mainly came from the graduated alumnus who used to be the MBA/EMBA students in their university and worked as the top managers of their respective companies. Since the concept of IT-enabled interaction is bilateral in nature, we collected dyadic data from both the supplier and the manufacturer by asking the respondents to invite one of their core suppliers to participate in the same survey. The questionnaires were answered based on the bilateral relation between the supplier and the manufacturer. Finally, we got 85 valid dyadic data with the valid return rate of $24 \%(85 / 350)$.

After we got the descriptions from the dyadic sample $(N=85 \times 2)$, we invited a research group to transform the respondents' descriptions to text for further coding and cataloguing. The research group consisted of two experts in marketing, one expert in information system, one expert in computer science and three PhD students. After sorting and then coding the respondents' answers on the questionnaire, the research group got 268 typical descriptions in total, which were further filtered after two rounds of item-to-item discussions following Churchill's [44] suggestion. We got 68 descriptions related to IT-enabled formal interaction and 62 descriptions were related to IT-enabled informal interaction. For further simplifying and cataloguing the descriptions related to the measurement, we adopted the qualitative analysis software ATLAS.TI 7.0 to conduct several rounds of inductive process separately. Then, we compared the findings with each other and got consistent taxonomy after discussion. The results reviewed 16 IT-enabled interaction dimensions, among which, eight items were related to IT-enabled formal interaction and the rest were related to IT-enabled informal interaction. In order to test the reliability of the finalized 16 items, we conducted a small-scale survey with $35 \mathrm{MBA}$ students in our school. Each respondent was randomly given 20 of the original 130 descriptive items and was asked to label them as one of the final 16 items. The consistency ratio reached up to $93 \%$, thus ensuring the face validity as well as the content validity of the item generation process.

\subsubsection{Items Derived from the Literature}

To test and potentially validate the scale of IT-enabled interactions, we compared the items derived empirically with those derived theoretically. Then we juxtaposed and integrated the items together to establish the preliminary item pool of IT-enabled interactions.

The procedure of how we reviewed literature on the existing measurement of IT-enabled interaction has been provided above in Section 2.4., "Measurement of IT-Enabled Interaction". We found 166 articles with typical descriptions of IT-enabled interactions, of which 48 publications had existing empirical scales with items describing patterns of activities or routines concerning firms interacting with each other. We invited another two students to conduct content analysis on the measuring items. Repetitive or overlapping items were deleted or merged together after several rounds of discussions. Following that, we used the theoretically derived items to juxtapose and integrate with the empirically derived items. The taxonomy derived from empirical analysis almost captures all descriptions in the literature. The considerable overlap provides evidence of the content validity of the scales developed previously. After comparison and discussion, we kept the items that better capture the definition of IT-enabled formal and informal interaction and added one item, Q23 "We often use information technologies for understanding trends in sales and customer preferences together", derived theoretically. One empirically derived item, Q7, was replaced by the theoretically derived item Q20 "We often 
coordinate the inventory (or production) plans with each other via IT". Three items of IT-enabled informal interaction-Q10, Q12 and Q15-were derived theoretically. The final preliminary item pool is presented in Table 3.

Table 3. The Preliminary IT-Enabled Interaction Item Pool.

\begin{tabular}{|c|c|}
\hline \multicolumn{2}{|c|}{ IT-Enabled Formal Interaction } \\
\hline Q1 & $\begin{array}{l}\text { Our company and the supplier often exchange business information with each other via IT } \\
\text { (e.g., DingTalk, e-mail). }\end{array}$ \\
\hline Q2 & We often transfer business materials with each other via IT (e.g., e-mail, PPT, DingTalk). \\
\hline Q3 & $\begin{array}{l}\text { We often transmit purchase orders with each other through information technologies } \\
\text { (e.g., ERP, Sametime). }\end{array}$ \\
\hline Q4 & We often pay for each other's invoices through IT-based support (e.g., Alipay). \\
\hline Q5 & We often track and/or expedite shipments through IT-based support. \\
\hline Q6 & We often access each other's inventory (or production) levels through information technologies. \\
\hline Q20 & We often coordinate the inventory (or production) plans via IT. \\
\hline Q8 & We hold video conferences on a regular basis. \\
\hline Q23 & $\begin{array}{l}\text { We often use information technologies for understanding trends in sales and customer } \\
\text { preferences together. }\end{array}$ \\
\hline \multicolumn{2}{|c|}{ IT-Enabled Informal Interaction } \\
\hline Q10 & We follow one another on social media. \\
\hline Q11 & Our company and the supplier use social software to enhance our relationship. \\
\hline Q12 & $\begin{array}{l}\text { We often interact on social media, such as posting or forwarding interesting links to one another, } \\
\text { making comments and "opting in." }\end{array}$ \\
\hline Q13 & We often play some online games together (e.g., online Poker) \\
\hline Q14 & We keep each other informed about interesting news, events or changes via social media. \\
\hline Q15 & We often chat about family or interests over the Internet with one another in our spare time. \\
\hline Q16 & We share common WeChat or QQ group(s) to strengthen our social bonds. \\
\hline Q17 & We interact with each other in common WeChat or QQ groups. \\
\hline
\end{tabular}

\subsection{Face and Content Validity}

We conducted a pretest with a focus group to check the face and content validity of the preliminary items [46]. The focus group consisted of four members, including two experts in marketing and two experts in information system. They evaluated the 17-item pool (including nine items measuring IT-enabled informal interaction and eight items measuring IT-enabled formal interaction) using a five-point Likert scale $(1=$ not reflect at all to $5=$ strongly reflect). The scale was used to evaluate to which degree the experts agree that each item could describe the construct of IT-enabled interaction across organizations. All the respondent's evaluated scores range between 4 (reflect) and 5 (strongly reflect). Therefore, the 17 items had high face and content validity and they were ready for the pilot study.

\subsection{The First and Small Scale Survey}

Following Churchill's suggestion [44], we collected two samples for item purification and refinement. The first dataset sample would be utilized as a small scale pilot study to purify the items and explore the constructive dimensions of IT-enabled interaction through empirical analysis. We collected data from MBA and EMBA students in manufacturing firms through face-to-face interviews. Of the 160 students who agreed to participate, 128 informants completed the survey, among which 120 questionnaires were valid (valid response rate $75 \%$ ). Of the valid samples, $62.5 \%$ were male and $37.5 \%$ were female, $80 \%$ had at least five years of working experience in the current firm. 
In terms of their position, $55 \%$ were chief executive officer (CEO) or vice-president, $30 \%$ were managers of the purchase department or technology department and 15\% were others such as middle-level managers. The sample of the pilot study was diverse and the all the respondents were chief managers dealing with the interactions with their suppliers.

\subsubsection{Preliminary Purification Via Item Analysis}

With the data collected from the sample, we first filtered the items through "critical value" and "correlation coefficient of the Item-to-Total score" using SPSS 20.0 [47]. The data analysis results suggest that the $t$ values of all items reached a significant level in the critical value test, suggesting that the discriminant validity is good. The Item-to-Total score suggests that four of the 17 items, namely, Q4, Q8, Q23 and Q13 as well as Q17 fall below the value of 0.4. The Cronbach's alpha of the pretest scale was 0.800 . The reliability of the entire scale could improve after dropping Q8 $(0.803>0.800)$, $\mathrm{Q} 23(0.802>0.800), \mathrm{Q} 13(0.809>0.800)$ and $\mathrm{Q} 17(0.801>0.800)$. All the above results suggest that the four items should be removed. However, after dropping Q4, the reliability of the entire scale would decline to $(0.792<0.800)$. Thus, $\mathrm{Q} 4$ was temporarily retained.

\subsubsection{Preliminary Purification Via Construct Validity Analysis (EFA)}

To further simplify the items and reveal the internal structure of IT-enabled formal and informal interactions, we conducted EFA using principal component analysis with Promax rotation to determine construct validity [47]. The Kaisere Meyere Olkin (KMO) measure and Bartlett's test of sphericity were used to ensure that the data attained sufficient inherent correlations for the EFA. The KMO index was 0.830 and the Bartlett's test of Sphericity yielded 617.383 and $p<0.01$, which justified the use of EFA. After gradual factorial exploration, the maximum load of Q4 was less than 0.50 , whereas the load of Q10 was greater than 0.35 in both factors. Both Q4 and Q10 failed to meet the standard and were deleted. The remaining items (Q1, Q2, Q3, Q5, Q6, Q20, Q11, Q12, Q14, Q15 and Q16) were examined for identifying the underlying factors using EFA with Promax rotation. Two common factors were extracted during this process. The eigen values were above 1 after extracting the two common factors (see Table 4). The cumulative variance contribution rate was $60.55 \%$, which met the basic qualifications. The first common factor comprised six items (Q1, Q2, Q3, Q5, Q6 and Q20). These items reflected the partnering firms' IT-aided, contract-based bilateral activities which are business-oriented and aimed at negotiating and safeguarding contracts. The second common factor comprised five items (Q11, Q12, Q14, Q15 and Q16), reflecting the partnering firms' bilateral socialization tactics beyond official trade settings via various social platforms. It can well capture the definition of IT-enabled informal interaction. We can find a similar assortment in prior literature, including interfirm formal and informal communication [48], IT adoption (formal interactions via IOS and informal interactions over social software) [15] and interfirm formal vs. informal governance strategy [49].

In conclusion, the measures of IT-enabled formal and informal interactions can well distinguish from each other. The scale of IT-enabled formal interaction included six items, while the scale of IT-enabled informal interaction was composed of five items. The reliability of IT-enabled formal interaction was 0.83 and the reliability of IT-enabled informal interaction was 0.88 , both of which met the basic qualifications. The correlation coefficients among the respective items of each scale were greater than 0.4 and could not be promoted after deleting any item. This finding implies high homogeneity in the items of teach scale. Therefore, the design of the IT-enabled formal and informal scales was reasonable and valid. 
Table 4. The exploratory factor analysis (EFA) results.

\begin{tabular}{clccc}
\hline & \multicolumn{1}{c}{ Items } & \multicolumn{2}{c}{ Factor } & Communalities \\
\cline { 2 - 3 } Q1 & $\begin{array}{l}\text { Our company and the supplier often exchange business information } \\
\text { with each other via IT (e.g., DingTalk, e-mail). }\end{array}$ & 0.68 & 0.09 & 0.47 \\
\hline Q2 & $\begin{array}{l}\text { We often transfer business materials with each other via IT } \\
\text { (e.g., e-mail, PPT, DingTalk). }\end{array}$ & 0.73 & 0.05 & 0.54 \\
\hline Q3 & $\begin{array}{l}\text { We often transmit purchase orders with each other through } \\
\text { information technologies (e.g., ERP, Sametime). }\end{array}$ & 0.76 & 0.05 & 0.58 \\
\hline Q5 & We often track and/or expedite shipments via IT-based support. & 0.81 & -0.04 & 0.66 \\
\hline Q6 & $\begin{array}{l}\text { We often access each other's inventory (or production) levels through } \\
\text { information technologies. }\end{array}$ & 0.70 & 0.10 & 0.49 \\
\hline Q20 & We often coordinate the inventory (or production) plans via IT. & 0.72 & 0.09 & 0.52 \\
\hline Q11 & $\begin{array}{l}\text { Our company and the supplier use social software to enhance } \\
\text { our relationship. }\end{array}$ & 0.01 & 0.84 & 0.71 \\
\hline Q12 & $\begin{array}{l}\text { We often interact on social media, such as posting or forwarding } \\
\text { interesting links to one another, making comments and “opting in.” }\end{array}$ & 0.08 & 0.82 & 0.69 \\
\hline Q14 & $\begin{array}{l}\text { We keep each other informed about interesting news, events or } \\
\text { changes via social media. }\end{array}$ & 0.12 & 0.80 & 0.65 \\
\hline Q15 & $\begin{array}{l}\text { We often chat about family or interests over the Internet with one } \\
\text { another in our spare time. }\end{array}$ & 0.08 & 0.80 & 0.64 \\
\hline Q16 & $\begin{array}{l}\text { We share common WeChat or QQ group(s) to strengthen our } \\
\text { social bonds. }\end{array}$ & 0.04 & 0.85 & 0.72 \\
\hline
\end{tabular}

\subsection{The Second and Final Questionnaire Survey}

We collected the second dataset from the graduated MBA and EMBA students in our school for the final validation of the instrument. First, we got a list of the head of the Alumni Association about the students' list, which presents the students' information. Of about 2000 MBA and EMBA students in the list, 520 firm managers in manufacturing firms in different sub-manufacturing industries were selected as the target, which is in line of the sample we used in the former two stages. After careful selection, we distributed the firms with the questionnaire with the help of the Alumni Association members. The questionnaire included the measurements of IT-enabled formal and informal interactions and interfirm knowledge sharing. The sample was mainly located in Jilin, Shaanxi and Guangdong provinces, where the manufacturing firms are relatively mature. We received a total of 396 questionnaires, among which 336 were valid ( $84.8 \%$ return rate).

Among the respondents who submitted valid survey forms, $62.5 \%$ were male and $37.5 \%$ were female, $77.4 \%$ had worked for at least six years and all of the respondents were high-level managers. In terms of age, $9.8 \%$ were under 30 years old; $40.3 \%$ were between 31 and 35 years old; $25 \%$ were between 36 and 40 years old; $19.9 \%$ were between 41 and 45 years old; and 5\% were above 46 years old. In terms of education, $25 \%$ had an education level lower than bachelor's degree, $55.1 \%$ had finished a bachelor's degree and $19.9 \%$ had attained a master's degree. Thus, the sample was highly diverse.

\subsubsection{Non-Response Bias Test}

We conducted two t-tests to check the non-response bias. The first t-test results reveal that no significant difference exists between the early and late $10 \%$ respondents in terms of the industry type $(t=-0.34)$, working experience at their respective companies $(t=0.22)$ and firm size $(t=-0.28)$. The second t-text analysis reveals that the online and offline samples have no significant difference in the above-mentioned characteristics: Industry type $(t=-0.37)$, working experience $(t=0.16)$ and firm size $(t=1.08)$. Therefore, the non-response bias is not a concern [50]. 


\subsubsection{Common Method Bias Test}

Following Podsakoff and his colleagues [51], the study employed Harmon one-factor analysis to check the potential existence of common method bias. EFA was conducted with principal components analysis and varimax rotation on all the items. The results revealed that there exist three factors with eigenvalues greater than 1 and they accounted for $69.8 \%$ of the total variance. The first factor only explained 11.2 percent of the total variance. Therefore, common method bias is not a big concern.

\section{Validation of IT-Enabled Interaction Instrument}

Using the large-scale sample we collected, we further refined the final instrument items via a series of item analyses. Then, the confirmatory factor analysis (CFA) was conducted to identify the internal construction of the scales of both IT-enabled formal and informal interactions. Then, we tested the predictive validity of the two scales by empirically checking their direct relationship with interfirm trust since prior studies had proven that IT-enabled formal interaction can improve interfirm trust [43] and IT-enabled informal interaction is conceptually supposed to be able to strengthen trust across boundary spanners from different partnering firms [21,22].

\subsection{Item Analysis}

A series of item analyses were performed using SPSS 20.0 to assess the appropriateness of the data in the IT-enabled formal and informal interaction scales we derived in the last stage. The $t$ value of each item reached significant levels with satisfactory distinction during the critical value examination. The correlation coefficient between the total score of the IT-enabled formal interaction scale and its own items are $0.76,0.76,0.81,0.72,0.76$ and 0.74 ; all of the values are above 0.7 , indicating a high standard of internal homogeneity of this scale; the correlation coefficient between the total score of the IT-enabled informal interaction scale and its own items are $0.85,0.82,0.72,0.77$ and 0.81 ; all of the values are above 0.7 , indicating that the scale of IT-enabled informal interaction also has a high standard of internal homogeneity. The Cronbach's alpha of the scale measuring IT-enabled formal interaction and that of IT-enabled informal interaction were the same of 0.85 , which denotes high consistency. The correlation coefficient between each item in either formal or informal types of IT-enabled interactions was above 0.4 and the reliability of each scale could decrease if any of the remaining items got deleted, supporting the reasonability of the item design.

\subsection{Confirmatory Factor Analysis (CFA)}

CFA was conducted using AMOS 18.0. First, as there might exist connections between the scale of IT-enabled formal and that of IT-enabled informal interactions, the authors first compared the composite reliability coefficients of the one-factor model with that of the two-factor model, the composite reliability coefficient of IT-enabled formal interaction was 0.86 and the composite reliability coefficient of IT-enabled informal interaction was 0.85 . Both the values are above 0.7 , indicating high inherent quality and enhancing construct reliability of the two-factor model. However, in the one-factor model, we found a poor fit index of this model, in which the root-mean-square error of approximation (RMSEA) was $0.178(>0.1)$ and the $\chi^{2} / \mathrm{df}$ was $11.67(>3)$, which did not satisfy the fit criteria. By contrast, the multiple criteria of the two-factor model were satisfactory, with all items almost reaching the optimal standard $\left(\chi^{2} / \mathrm{df}=2.30, p<0.001\right.$; confirmatory fit index $(\mathrm{CFI})=0.96$; incremental fit index $(\mathrm{IFI})=0.96$; Tacker-Lewis index $(\mathrm{TLI})=0.95$; root mean square error of approximation $($ RMSEA $)=0.062$ ). This result indicated that the two-factor model showed the best fit indices among the estimated models, thus reaffirming the superiority of the two-factor model.

Standard factor loading and average variance extraction (AVE) were adopted to further evaluate the convergent validity of the two-factor model. Table 5 shows that the standard factor loadings of all items ranged from 0.65 to 0.82 . The AVE values of both IT-enabled formal and informal 
interactions were no less than $0.5(0.501 ; 0.539)$. These results suggested that both the scales have good convergent validity.

Table 5. The confirmatory factor analysis (CFA) results $(N=336)$.

\begin{tabular}{|c|c|c|c|c|}
\hline Variables and Items & $\begin{array}{l}\text { Factor } \\
\text { Loading }\end{array}$ & $\alpha$ & AVE & CR \\
\hline IT-enabled formal interaction & & 0.85 & 0.50 & 0.86 \\
\hline $\begin{array}{l}\text { Q1. Our company and the supplier often exchange business information } \\
\text { with each other via IT (e.g., DingTalk, e-mail). }\end{array}$ & 0.65 & & & \\
\hline $\begin{array}{l}\text { Q2. We often transfer business materials with each other via IT } \\
\text { (e.g., e-mail, PPT, DingTalk). }\end{array}$ & 0.72 & & & \\
\hline $\begin{array}{l}\text { Q3. We often transmit purchase orders with each other through } \\
\text { information technologies (e.g., ERP, Sametime). }\end{array}$ & 0.71 & & & \\
\hline Q5. We often track and/or expedite shipments via IT-based support. & 0.78 & & & \\
\hline $\begin{array}{l}\text { Q6. We often access each other's inventory (or production) levels through } \\
\text { information technologies. }\end{array}$ & 0.66 & & & \\
\hline Q20. We often coordinate the inventory (or production) plans via IT. & 0.72 & & & \\
\hline IT-enabled Informal Interactions & & 0.85 & 0.54 & 0.85 \\
\hline $\begin{array}{l}\text { Q11. Our company and the supplier use social soft wares to enhance } \\
\text { our relationship. }\end{array}$ & 0.82 & & & \\
\hline $\begin{array}{l}\text { Q12. We often interact on social media, such as posting or forwarding } \\
\text { interesting links to one another, making comments and "opting in." }\end{array}$ & 0.76 & & & \\
\hline $\begin{array}{l}\text { Q14. We keep each other informed about interesting news, } \\
\text { events or changes via social media. }\end{array}$ & 0.65 & & & \\
\hline $\begin{array}{l}\text { Q15. We often chat about family or interests over the Internet with one } \\
\text { another in our spare time. }\end{array}$ & 0.71 & & & \\
\hline $\begin{array}{l}\text { Q16. We share common WeChat or QQ group(s) to strengthen our } \\
\text { social bonds. }\end{array}$ & 0.72 & & & \\
\hline \multicolumn{5}{|l|}{ Model Fit } \\
\hline \multicolumn{5}{|c|}{$\begin{array}{c}\chi^{2}=98.705, \mathrm{Df}=43, \chi^{2} / \mathrm{df}=2.295, p<0.001 ; \mathrm{CFI}=0.96 ; \mathrm{IFI}=0.96 ; \mathrm{TLI}=0.95 ; \mathrm{RMSEA}=0.062 ; \mathrm{NFI}=0.94 ; \\
\mathrm{RFI}=0.92\end{array}$} \\
\hline
\end{tabular}

Since there are two constructs in this model, we employed structural equation modeling (SEM) to examine the discriminant validity of the scales. The chi-square value of "IT-enabled formal interaction-IT-enabled informal interaction" in the unrestricted model was 1565.58 and the degree of freedom (df) was 55. The chi-square value of the restricted model was 98.71 and the $\mathrm{df}$ was 43 . The D-value of the chi-square values of the two models was 1466.87 and the D-value of the $\mathrm{df}$ was 12 . From the significance test table of the chi-square D-value, the significance of the chi-square difference of the two models was $p<0.001$, which indicated a significant difference between the "restricted" and "unrestricted" models. Compared with the "restricted model", the "unrestricted model" showed lower chi-square value. These findings provide solid evidence for the discriminant validity between "IT-enabled formal interaction" and "IT-enabled informal interaction."

\subsection{Predictive Validity}

The final step in instrument validation was to test the predictive validity, which indicates the degree to which the generated measurement is associated with the other factors (such as the consequent factor) in the way that it should be theoretically [44]. Since prior literature has suggested that IT-enabled formal and informal interaction can help to cultivate mutual trust across partnering firms [21,22,43], this study selects interfirm trust as the dependent variable to test the predictive validity of the two 
scales. Trust refers to the degree to which organization members maintain a collective trust orientation toward the partnering firm [52]. This study measures trust with three items, which reflect the degree to which the partnering firms believe in each other's good faith, reliability and overall honesty [52].

We first conducted a CFA analysis to check the validity of the measurement model using the AMOS 18.0 software and got a satisfactory model $\left(\chi^{2} / \mathrm{df}=2.15, p<0.001\right.$; confirmatory fit index (CFI) $=0.96$; incremental fit index $(\mathrm{IFI})=0.96$; Tacker-Lewis index $(\mathrm{TLI})=0.95$; root mean square error of approximation $($ RMSEA $)=0.055)$. Most of the standardized factor loading of each item is above or nearly 0.7. The Cronbach's alpha of each scale was all above 0.8, the AVE value of each construct was above 0.5 and the construct reliability of each scale was above 0.8 , thus providing evidence for the convergent and discriminant validity of all the three constructs (see Table 6).

Table 6. Model fit of the prediction model.

\begin{tabular}{|c|c|c|c|c|}
\hline Variables and Items & $\begin{array}{l}\text { Factor } \\
\text { Loading }\end{array}$ & $\alpha$ & AVE & CR \\
\hline IT-enabled formal interaction & & 0.83 & 0.50 & 0.86 \\
\hline $\begin{array}{l}\text { Q1. Our company and the supplier often exchange business information } \\
\text { with each other via IT (e.g., DingTalk, e-mail). }\end{array}$ & 0.64 & & & \\
\hline $\begin{array}{l}\text { Q2. We often transfer business materials with each other via IT } \\
\text { (e.g., e-mail, PPT, DingTalk). }\end{array}$ & 0.72 & & & \\
\hline $\begin{array}{l}\text { Q3. We often transmit purchase orders with each other through } \\
\text { information technologies (e.g., ERP, Sametime). }\end{array}$ & 0.70 & & & \\
\hline Q5. We often track and/or expedite shipments via IT-based support. & 0.80 & & & \\
\hline $\begin{array}{l}\text { Q6. We often access each other's inventory (or production) levels through } \\
\text { information technologies. }\end{array}$ & 0.66 & & & \\
\hline Q20. We often coordinate the inventory (or production) plans via IT. & 0.72 & & & \\
\hline IT-enabled Informal Interactions & & 0.85 & 0.54 & 0.85 \\
\hline $\begin{array}{l}\text { Q11. Our company and the supplier use social software to enhance } \\
\text { our relationship. }\end{array}$ & 0.82 & & & \\
\hline $\begin{array}{l}\text { Q12. We often interact on social media, such as posting or forwarding } \\
\text { interesting links to one another, making comments and "opting in." }\end{array}$ & 0.76 & & & \\
\hline $\begin{array}{l}\text { Q14. We keep each other informed about interesting news, } \\
\text { events or changes via social media. }\end{array}$ & 0.66 & & & \\
\hline $\begin{array}{l}\text { Q15. We often chat about family or interests over the Internet with one } \\
\text { another in our spare time. }\end{array}$ & 0.71 & & & \\
\hline $\begin{array}{l}\text { Q16. We share common WeChat or QQ group(s) to strengthen our } \\
\text { social bonds. }\end{array}$ & 0.72 & & & \\
\hline Trust & & 0.89 & 0.72 & 0.90 \\
\hline We regard each other trustworthy. & 0.82 & & & \\
\hline We can guarantee each other's good faith. & 0.86 & & & \\
\hline Overall, we trust each other. & 0.88 & & & \\
\hline \multicolumn{5}{|l|}{ Model Fit (without Q2, Q5) } \\
\hline \multicolumn{5}{|c|}{$\begin{array}{c}\chi^{2}=167.53, \mathrm{Df}=78, \chi^{2} / \mathrm{df}=2.15, p<0.001 ; \mathrm{CFI}=0.96 ; \mathrm{IFI}=0.96 ; \mathrm{TLI}=0.95 ; \mathrm{RMSEA}=0.055 ; \mathrm{NFI}=0.93 ; \\
\mathrm{RFI}=0.91\end{array}$} \\
\hline
\end{tabular}

Next, we tested the predictive validity of IT-enabled formal and informal interactions with SEM analysis using the AMOS 18.0 software. While there are only three measurements in this mode, it is more reasonable to conduct SEM analysis than the regression analysis due to the potential correlation between IT-enabled formal and informal interactions [53]. The model was satisfactory $\left(\chi^{2} / \mathrm{df}=2.15\right.$, $p<0.001$; confirmatory fit index $(\mathrm{CFI})=0.96$; incremental fit index $(\mathrm{IFI})=0.96$; Tacker-Lewis index 
$(T L I)=0.95$; root mean square error of approximation $($ RMSEA $)=0.055)$. The authors found that both IT-enabled formal interaction ( $\beta=0.30, p<0.01)$ and IT-enabled informal interaction $(\beta=0.18, p<0.05)$ exhibited significant positive correlations with cross-organizational trust. These results indicate the excellent predictive validity of the developed IT-enabled formal and informal interaction scales.

In addition, to double check the predictive validity of the scales, we performed a robustness test with the first dataset which collected 120 dyadic data from both the supplier and the buyer. The value of each variable was calculated by the average of the answer provided by both parties on the Likert scale. After checking the validity of the measurement model using AMOS 18.0 software, SEM analysis was conducted. The results suggest that the model is satisfactory $\left(\chi^{2} / \mathrm{df}=1.67, p<0.001\right.$; confirmatory fit index $(\mathrm{CFI})=0.94$; incremental fit index $(\mathrm{IFI})=0.93$; Tacker-Lewis index $(\mathrm{TLI})=0.93$; root mean square error of approximation (RMSEA) $=0.067)$. Both IT-enabled formal interaction $(\beta=0.34, p<0.01)$ and IT-enabled informal interaction $(\beta=0.28, p<0.01)$ have positive and significant impacts on cross-organizational trust, thus providing evidence of the robustness of the predictive validity.

\section{Findings}

This study provides reliable and valid scales to measure IT-enabled formal and informal interactions for the contemporary Chinese context. A mix method including both qualitative and quantitative tactics was employed to generate the scales following the procedure suggested by prior literature [44]. First, the results of EFA confirm that IT-enabled interaction comprises both unstructured formal communication facilitated by IT software and programs (Q1, Q2) and structured formal interactions automated by information systems (Q3, Q5, Q6, Q20). All six items in the final instrument can well capture the definition of IT-enabled formal interaction, i.e., contact-related, business-oriented activities in which partners focus on negotiating and communicating over contracts. Among the six items, Q1, Q2 and Q5 are newly provided in this study. Q1 and Q2 are mainly utilized to measure the unstructured business communication over IT applications. Q5 measure the degree to which firms utilize IT (including information systems and website based on our interview results) to track and/or expedite shipments. The scale of IT-enabled informal interaction contains five items, which are relation-oriented activities and partners mainly transmit social signals to each other in those interactions. Compared with the instrument provided previously by Li and her colleagues [13], we add three new items for the measurement of IT-enabled informal interaction: "Q11. Our company and the supplier use social software to enhance our relationship."; "Q14. We keep each other informed about interesting news, events or changes via social media."; and "Q16. We share common WeChat or QQ group(s) to strengthen our social bonds". In addition, this study tests the effects of IT-enabled formal and informal interactions on knowledge sharing and the results further provide evidence for the validity of the scales.

\section{Conclusions}

\subsection{Theoretical Implications}

This study may contribute to prior literature on IT-enabled interaction in three aspects. First, by testing and validating the scale of IT-enabled formal interaction in the contemporary Chinese context, this study provides a more time-efficient measurement of this construct. While prior researchers studied IT-enabled formal interaction from different perspectives, they focus on either structured business integration automated by EDI platforms or unstructured business communication facilitated by a single IT tool, and thus fail to provide a holistic understanding of IT-enabled formal interaction. Besides, the measurement of the formal type of IT-enabled interaction could not capture the rapid development and widespread adoption of new IT applications in China in the last five years, such as DingTalk, Cloud Computing and Alipay. Compared with the measurement in prior literature, this study adds three new items to measure IT-enabled formal interaction: "Our company and the supplier often exchange business information with each other via IT (e.g., DingTalk, e-mail)"; "We often 
transfer business materials with each other via IT (e.g., e-mail, PPT, DingTalk)"; and "We often track and/or expedite shipments through IT-based support". Our scale shows advantage over the one in prior literature by providing a more complete understanding of IT-enabled formal interaction for contemporary Chinese context.

Second, this study updated and modified the instrument to measure IT-enabled informal interaction. Prior literature has paid great attention to IT-enabled formal interaction while largely ignore the role of IT-enabled formal interaction. Only four studies investigate IT-enabled informal interaction, among which three studies were conducted in foreign contexts using the qualitative analysis method. Only Li and her colleagues [13] provide the scale to measure IT-enabled informal interaction. However, by the time that study was conducted, many applications such as WeChat Moments had not been widely adopted by top managers in China. Thus, that scale should be updated and modified. Using data collected in 2018 and 2019, this study adds three new items, i.e., "Our company and the supplier use social software to enhance our relationship"; "We keep each other informed about interesting news, events or changes via social media"; and "We share common WeChat or QQ group(s) to strengthen our social bonds". This scale can improve our understanding of IT-enabled informal interaction for the contemporary Chinese context.

Third, by empirically testing the impact of IT-enabled informal interaction on interfirm trust, this study enriches research on IT-enabled informal interactions. The majority of prior researchers focused on IT-enabled formal interaction while largely overlooking the role of IT-enabled informal interaction. While prior researchers conceptually state that IT-enabled informal interaction might cultivate mutual trust across partners via in-depth interviews [21,22], they did not provide empirical support for that argument. This study enriches prior literature on IT-enabled informal interaction by empirically investigating its direct impact on cross-organizational trust.

\subsection{Managerial Implications}

Under the grant version of Industry 4.0, the policy of Made in China 2025 and the breakout of novel coronavirus in 2019, interfirm interactions have dramatically shifted from offline to the IT-based channels [4,5]. However, the IT applications in China differ greatly from those in foreign companies [6], which may make managers confused when utilizing IT for interfirm interactions. By developing the instrument of IT-enabled interaction in the current Chinese context, this study might help to guide firm managers to better understand the IT-enabled interaction typology and features in interfirm relationship management in China. Specifically, the instrument of IT-enabled formal interaction could be used by practitioners to study the to-be-developed or to-be-implemented activities over IT tools, which is supposed to improve green business management. According to our findings, IT-facilitated shipment tracking and business communication over IT applications such as DingTalk have become increasingly prevalent in China. Firm managers should consider using such advanced digital tools to negotiate contracts with each other. Second, besides IT-enabled formal interactions, the informal IT-enabled interactions are also a key asset for intefirm relationship management. As firms increasingly socialize with each other using IT, especially the social platforms such as Twitter and WeChat, firms need to understand which activities they perform over those social platforms can help to strengthen interfirm relationships. The developed scale of IT-enabled informal interaction provide a measurement model that can test which aspects of a firm's online interactive activities are able to affect interfirm relationship management and therefore firm managers should pay attention to such activities, especially the interactions involving third parties on WeChat Moments and WeChat groups. Finally, besides formal types of IT-enabled interaction, firms should leverage informal type of IT-enabled interaction to enhance cross-organizational trust.

\section{Suggestions for Future Investigations}

This study carries the following limitations, which can serve as the directions for future research. First, the scales developed in this study focus mainly on the electronic-hierarchy rather 
than the electronic-market context and excluded the samples on electronic markets such as Alibaba. The interaction modes under the two contexts differ significantly from each other [34]. Future researchers can develop the scale of IT-enabled interactions in the electronic market context. Second, the concept of IT-enabled interaction is bilateral in nature. However, data used for the large-scale analysis in this study was collected solely from the manufacturer's side within the supplier-manufacturer relationships. Future research on IT-enabled interactions could collect data from both the supplier and the manufacturer to develop and improve the measurement scale designed in this study. Finally, inter-organizational trust can be categorized into different types, such as benevolence-based or competence-based trust [54]. However, this study regards trust as a holistic concept. Future studies may check the impacts of IT-enabled formal and informal interactions on different type of trust for a better understanding of the different roles of the two types of IT-enabled interactions in cultivating mutual trust across partner firms.

Author Contributions: M.L. conceived the original idea of this research. All authors contributed to the writing of this manuscript. M.L. supported the review of the writing and final version of data analysis. C.L. supported data collection. X.Y. contributed to the analysis of the conclusions. All authors have read and agreed to the published version of the manuscript.

Funding: This work was founded by the Fundamental Research Funds for the Central Universities in Jilin University (Grant number 2019ZZ019) and the Humanities and Social Science Foundation of Ministry of Education of China (Grant number 20YJA630028).

Conflicts of Interest: The authors declare no conflict of interest.

\section{References}

1. Grönroos, C. A service perspective on business relationships: The value creation, interaction and marketing interface. Ind. Mark. Manag. 2011, 40, 240-247. [CrossRef]

2. Gundlach, G.T.; Frankel, R.; Krotz, R.T. Competition policy and antitrust law: Implications of developments in supply chain management. J. Supply Chain Manag. 2019, 55, 47-67. [CrossRef]

3. Ramani, G.; Kumar, V. Interaction orientation and firm performance. J. Mark. 2008, 72, 27-45. [CrossRef]

4. Liu, S.; Wang, X.; Wang, T. Enterprise Big Data under Industry 4.0-Rediscovering the Treasure; Electronic Industry Press: Beijing, China, 2016.

5. 2016 China Social Application User Behavior Research Report. Available online: http://www.cnnic.net.cn/ hlwfzyj/hlwxzbg/sqbg/201712/P020180103485975797840.pdf (accessed on 20 April 2019).

6. Whitepaper: China Internet Overview. Available online: https://www.chinainternetwatch.com/whitepaper/ china-internet-statistics (accessed on 15 December 2019).

7. Kankanhalli, A.; Tan, B.C.Y.; Wei, K. Conflict and performance in global virtual teams. J. Manag. Inf. Syst. 2014, 23, 237-274. [CrossRef]

8. Keengwe, J.; Kidd, T.; Kyei-Blankson, L. Faculty and technology: Implications for faculty training and technology leadership. J. Sci. Edu. Tech. 2009, 18, 23-28. [CrossRef]

9. Han, K.; Kauffman, R.J.; Nault, B.R. Relative importance, specific investment and ownership in interorganizational systems. Inf. Tech. Manag. 2008, 9, 181-200. [CrossRef]

10. Jean, R.; Sinkovics, R.R.; Kim, D. Information technology and organizational performance within international business to business relationships: A review and an integrated conceptual framework. Int. Mark. Rev. 2008, 25, 563-583. [CrossRef]

11. Chen, D.Q.; Preston, D.S.; Xia, W. Enhancing hospital supply chain performance: A relational view and empirical test. J. Oper. Manag. 2013, 31, 391-408. [CrossRef]

12. Sinkovics, R.R.; Jean, R.B.; Roath, A.S.; Cavusgil, S.T. Does IT integration really enhance supplier responsiveness in global supply chains? Manag. Int. Rev. 2011, 51, 193-212. [CrossRef]

13. Li, M.; Zheng, X.; Zhuang, G. Information technology-enabled interactions, mutual monitoring, and supplier-buyer cooperation: A network perspective. J. Bus. Res. 2017, 78, 268-276. [CrossRef]

14. MaAfee, A. Mastering the three worlds of information technology. Harv. Bus. Rev. 2006, 8, 141-149. 
15. Schlagwein, D.; Prasarnphanich, P. Cultural Determinants of Organizational Social Media Adoption. In Proceedings of the 19th European Conference on Information Systems, ECIS 2011, Helsinki, Finland, 9-11 June 2011.

16. Chu, Y.; Chi, M.; Wang, W.; Luo, B. The impact of information technology capabilities of manufacturing enterprises on innovation performance: Evidences from SEM and fsQCA. Sustainability 2019, 11, 5946. [CrossRef]

17. Wang, E.T.; Wei, H.L. Interorganizational governance value creation: Coordinating for information visibility and flexibility in supply chains. Decis. Sci. 2007, 38, 647-674. [CrossRef]

18. Ward, P.; Zhou, H. Impact of information technology integration and lean/just-in-time practices on lead-time performance. Decis. Sci. 2006, 37, 177-203. [CrossRef]

19. Li, M.; Yan, F.; Li, C.; Zhang, F. Developing and validating the instrument of IT-enabled interaction in Chinese context. In Proceedings of the The 8th ISCIIA and 12th ITCA, Tengzhou, China, 2-6 November 2018.

20. Sigfusson, T.; Chetty, S. Building international entrepreneurial virtual networks in cyberspace. J. World Bus. 2012, 48, 260-270. [CrossRef]

21. Fischer, E.; Reuber, A.R. Social interaction via new social media: (How) can interactions on Twitter affect effectual thinking and behavior? J. Bus. Vent. 2011, 26, 1-18. [CrossRef]

22. Quinton, S.; Wilson, D. Tensions and ties in social media networks: Towards a model of understanding business relationship development and business performance enhancement through the use of LinkedIn. Ind. Mark. Manag. 2016, 54, 15-24. [CrossRef]

23. Sun, L.; Li, L.; Yue, C.; Kong, Y. Information interaction capabilities: Conceptualisation and instrument development. Tech. Anal. Stra. Manag. 2017, 29, 701-716. [CrossRef]

24. Li, T.; Chan, Y.E. Dynamic information technology capability: Concept definition and framework development. J. Stra. Inf. Syst. 2019, 28, 101575. [CrossRef]

25. Zaheer, A.; Venkatraman, N. Determinants of Electronic Integration in the Insurance Industry: An Empirical Test. Manag. Sci. 1994, 40, 549-566. [CrossRef]

26. Wang, E.T.; Tai, J.C.; Wei, H.L. A virtual integration theory of improved supply-chain performance. J. Manag. Inf. Syst. 2006, 23, 41-64. [CrossRef]

27. Wong, C.W.Y.; Lai, K.; Cheng, T.C.E.; Lun, Y.H.V. The role of IT-enabled collaborative decision making in inter-organizational information integration to improve customer service performance. Int. J. Prod. Econ. 2015, 159, 56-65. [CrossRef]

28. Choe, J. Inter-organizational relationships and the flow of information through value chains. Inf. Manag. 2008, 45, 444-450. [CrossRef]

29. Thomas, E. Supplier integration in new product development: Computer mediated communication, knowledge exchange and buyer performance. Ind. Mark. Manag. 2013, 42, 890-899. [CrossRef]

30. Cui, D.; Wu, F. New channels, new ways of becoming informed? Examining the acquisition of public affairs knowledge by young people in China. Inf. Dev. 2019, 35, 688-702.

31. China's Mobile Business Apps Users Insights 2018. Available online: https://www.chinainternetwatch.com/ 27253/mobile-business-apps-users-2018 (accessed on 7 November 2018).

32. Chen, S.; Shao, B.; Zhi, K. Examining the Effects of Passive WeChat Use in China. Int. J. Hum.-Comput. Int. 2019, 35, 1630-1644. [CrossRef]

33. Straub, D.W. Validating instruments in MIS research. MIS Q. 1989, 13, 147-169. [CrossRef]

34. Malone, T.W.; Yates, J.; Benjamin, R.I. Electronic markets and electronic hierarchies. Commun. ACM 1987, 30, 484-497. [CrossRef]

35. Webster, J.; Watson, R.T. Analyzing the past to prepare for the future: Writing a literature review. MIS Q. 2002, 26, xiii-xxiii.

36. Bensaou, M. Interorganizational cooperation: The role of information technology an empirical comparison of US and Japanese supplier relations. Inf. Syst. Res. 1997, 8, 107-124. [CrossRef]

37. Paulraj, A.; Lado, A.A.; Chen, I.J. Inter-organizational communication as a relational competency: Antecedents and performance outcomes in collaborative buyer-supplier relationships. J. Oper. Manag. 2008, 26, 45-64. [CrossRef]

38. Hill, C.A.; Scudder, G.D. The use of electronic data interchange for supply chain coordination in the food industry. J. Oper. Manag. 2002, 20, 375-387. [CrossRef] 
39. Kim, K.K.; Umanath, N.S.; Kim, B.H. An assessment of electronic information transfer in B2B supply-channel relationships. J. Manag. Inf. Syst. 2005, 22, 294-320. [CrossRef]

40. Wang, E.T.; Tai, J.C.; Grover, V. Examining the relational benefits of improved interfirm information processing capability in buyer-supplier dyads. MIS Q. 2013, 37, 149-173. [CrossRef]

41. Dong, S.; Xu, S.X.; Zhu, K.X. Research note-Information technology in supply chains: The value of IT-enabled resources under competition. Inf. Syst. Res. 2009, 20, 18-32. [CrossRef]

42. Lee, R.P.; Johnson, J.L.; Tang, X. An investigation into the role of IT integration, relationship predictability and routinization in interfirm relationships: From the structuration perspective. Ind. Mark. Manag. 2012, 41, 368-377. [CrossRef]

43. Rai, A.; Lang, S.S.; Welker, R.B. Assessing the validity of IS success models: An empirical test and theoretical analysis. Inf. Syst. Res. 2012, 13, 50-69. [CrossRef]

44. Churchill, G.A. A paradigm for developing better measures of marketing constructs. J. Mark. Res. 1979, 16, 64-73. [CrossRef]

45. Mustika, P.L.K.; Birtles, A.; Welters, R.; Marsh, H. The economic influence of community-based dolphin watching on a local economy in a developing country: Implications for conservation. Ecol. Econ. 2012, 79, 11-20. [CrossRef]

46. Ho, H.; Ganesan, S. Does knowledge base compatibility help or hurt knowledge sharing between suppliers in coopetition? The role of customer participation. J. Mark. 2013, 77, 91-107. [CrossRef]

47. Wu, M. Statistical Analysis of Questionnaire: SPSS Operation and Application; Chongqing University Press: Chongqing, China, 2010.

48. Håkansson, H. International Marketing and Purchasing of Industrial Goods: An Interaction Approach; John Wiley and Sons, Ltd.: Chichester, UK, 1982.

49. Styles, C.; Ambler, T. The coexistence of transaction and relational marketing: Insights from the Chinese business context. Ind. Mark. Manag. 2003, 32, 633-642. [CrossRef]

50. Armstrong, J.S.; Overton, T.S. Estimating nonresponse bias in mail surveys. J. Mark. Res. 1977, 14, $396-402$. [CrossRef]

51. Podsakoff, P.M.; Mackenzie, S.B.; Lee, J.Y.; Podsakoff, N.P. Common method biases in behavioral research: A critical review of the literature and recommended remedies. J. Appl. Psychol. 2003, 88, 879-903. [CrossRef] [PubMed]

52. Zaheer, A.; McEvily, B.; Perrone, V. Does trust matter? Exploring the effects of interorganizational and interpersonal trust on performance. Orga. Sci. 1998, 9, 141-159. [CrossRef]

53. Kline, R.B. Principles and Practice of Structural Equation Modeling; Guilford Press: New York, NY, USA, 1998.

54. Poppo, L.; Zenger, T. Do formal contracts and relational governance function as substitutes or complements? Stra. Manag. J. 2002, 23, 707-725. [CrossRef]

Publisher's Note: MDPI stays neutral with regard to jurisdictional claims in published maps and institutional affiliations.

(C) 2020 by the authors. Licensee MDPI, Basel, Switzerland. This article is an open access article distributed under the terms and conditions of the Creative Commons Attribution (CC BY) license (http://creativecommons.org/licenses/by/4.0/). 